\title{
Prolactin and breast increase during pregnancy in PCOS: linked to long-term metabolic health?
}

\author{
Maria Othelie Underdal ${ }^{1,2}$, Øyvind Salvesen ${ }^{3}$, Anne Schmedes ${ }^{4}$, Marianne Skovsager Andersen $^{5}$ and \\ Eszter Vanky ${ }^{1,2}$
}

1Department of Clinical and Molecular Medicine, Faculty of Medicine and Health Sciences, Norwegian University of Science and Technology, Trondheim, Norway, ${ }^{2}$ Department of Obstetrics and Gynecology, St. Olavs Hospital, University Hospital of Trondheim, Trondheim, Norway, ${ }^{3}$ Department of Public Health and Nursing, Faculty of Medicine and Health Sciences, Norwegian University of Science and Technology, Trondheim, Norway, ${ }^{4}$ Department of Biochemistry and Immunology, Lillebaelt Hospital, Vejle, Denmark, and ${ }^{5}$ Department of Internal Medicine, Odense University Hospital, Odense, Denmark

Correspondence should be addressed to M O Underdal Email

maria.o.underdal@ntnu.no

\begin{abstract}
Objective: To explore whether gestational prolactin and breast increase are markers of metabolic health in pregnancy and on long-term, in PCOS.

Design: Follow-up study. Women with PCOS, according to the Rotterdam criteria $(n=239)$, former participants of the randomized controlled trial (RCT) PregMet were invited, 131 participated in the current follow-up study, at mean 8 years after pregnancy.

Methods: Metformin $2000 \mathrm{mg} /$ day or placebo from first trimester to delivery in the original RCT. No intervention in the current study.

Prolactin was analyzed in the first trimester and at gestational week 32 and metabolic characteristics which are part of the metabolic syndrome and measures of glucose homeostasis were examined. Metabolic health was also evaluated according to breast increase versus lack of breast increase during pregnancy.

Results: Prolactin increase in pregnancy was negatively correlated to BMI $(P=0.007)$ and systolic blood pressure $(P \leq 0.001)$ in gestational week 32. Prolactin at gestational week 32 was negatively correlated to $\mathrm{BMI}(P=0.044)$ and visceral fat area $(P=0.028)$ at 8-year follow-up in an unadjusted model. Prolactin at gestational week 32 showed no associations to metabolic health at follow-up when baseline BMI was adjusted for. Women who reported lack of breast increase during pregnancy, had higher BMI $(P=0.034)$, waist-hip ratio $(P=0.004)$, visceral fat area $(P=0.050)$, total cholesterol $(P=0.022)$, systolic $(P=0.027)$ and diastolic blood pressure $(P=0.011)$ at 8 -year follow-up.

Conclusion: High prolactin levels and breast increase in pregnancy were associated with a more favorable long-term metabolic health in women with PCOS. Both prolactin and breast increase may be mediated by gestational BMI.
\end{abstract}

\section{Introduction}

Polycystic ovary syndrome (PCOS) is the most prevalent endocrine condition in women, with implications mainly for reproductive and metabolic health (1). Most women with PCOS have insulin resistance and hyperandrogenism $(2,3)$. These women are at increased risk of cardiovascular (c) 2019 European Society of Endocrinology Printed in Great Britain disease already during premenopausal years (4). In PCOS pregnancies, increased risk of gestational diabetes mellitus $(G D M)$, preterm birth and preeclampsia has been reported $(5,6,7)$. However, the high number of women with GDM might be linked to higher BMI in women with PCOS (8).

Published by Bioscientifica Ltd. 
Development and differentiation of the mammary glands and successive lactogenesis depend on prolactin. As a physiological adaptation to the emerging insulin resistance in pregnancy, prolactin stimulates $\beta$-cell proliferation in pancreatic islets (9). In non-pregnant women with PCOS, prolactin within normal range was inversely associated with metabolic risk markers such as waist circumference, total cholesterol, triglyceride and low-density lipoprotein (10). Furthermore, high prolactin within normal range was associated with lower prevalence of diabetes and impaired glucose tolerance in a large population-based cohort (11). Baseline prolactin was not associated to cardiovascular (CVD) risk profile at follow-up in women, around 40 years of age at inclusion, attending a longitudinal community-based cohort study on CVD risk factors (12).

We have previously reported that lack of breast increase during pregnancy was linked to poorer metabolic health both in early and late pregnancy compared to women with breast increase among women with PCOS (13). Breastfeeding duration is shorter in obese women, than in normal-weight women in the general population $(14,15)$. Shorter breastfeeding duration has also been reported in women with PCOS compared to women without PCOS (16). A large cohort study from Australia showed similar results, but the association between short breastfeeding and PCOS diminished after adjustment for BMI. Obesity might thus be a major contributing factor to shorter breastfeeding in women with PCOS (17).

Metformin is an insulin-sensitizer and is the first drug of choice in type 2 diabetes. According to the recent international evidence-based guidelines on treatment of PCOS, metformin could be considered in addition to lifestyle changes, to improve weight, hormonal and metabolic outcomes in adult non-pregnant women with PCOS (18). In pregnant women with PCOS, use of metformin reduced the prevalence of late miscarriage and preterm delivery (19).

Both prolactin levels and breast increase in pregnancy may be useful as long-term risk markers for metabolic health in women with PCOS. At present, androgen status and obesity are suggested as tools in individual risk-assessment of metabolic health in PCOS; however, metabolic disturbances are also increased in nonhyperandrogenic PCOS and we currently have no optimal predictors for detecting those at increased risk of metabolic and cardiovascular morbidity $(20,21)$.

In the present study, we aimed to explore if prolactin and breast increase during pregnancy are associated with metabolic health in pregnancy and on long term in women with PCOS. We also investigated whether metformin affected serum prolactin levels in pregnancy.

\section{Subjects and methods}

\section{Study design}

The PregMet study and later follow-up studies

In the current study, we analyzed data from the original PregMet study (22) and two follow-up studies (Fig. 1). The first follow-up focused on breast increment and participants provided self-reported data (13). At the second follow-up on metabolic health, participants met for follow-up examination at mean 8 years after the original study (23).

The PregMet study was a randomized, controlled, double-blind, multicenter trial performed 2005-2009, exploring the efficacy of metformin to reduce pregnancy complications in women with PCOS. Criteria permitting inclusion in the PregMet study were (1) PCOS diagnosed according to the Rotterdam criteria (24), (2) age 18-45 years, (3) gestational age between 5 and 12 weeks and (4) a singleton, viable fetus shown on ultrasonography. Details on randomization, blinding and examination are described elsewhere (22). In the PregMet study, 274 pregnancies in 257 women were assigned to an oral dose of metformin $2 \mathrm{~g}$ /day or placebo from first trimester of pregnancy and until delivery. All participants received individual verbal and written diet and lifestyle advice. Blood pressure was measured after at least $10 \mathrm{~min}$ of rest; measured three times with 2 min apart and the mean of the second and third measurement was calculated. Weight and height were measured with light clothes on.

Participants in the PregMet study gave their consent to be contacted after the initial study, for possible follow-up studies. One-year post-partum, participants $(n=240)$ were asked to complete a questionnaire on breast increment and breastfeeding. Participants who miscarried $(n=3)$, dropped-out $(n=12)$ or had lost their child $(n=2)$ were not approached. Bra size was recorded as bra cup size $(\mathrm{A}=1 ; \mathrm{B}=2 ; \mathrm{C}=3 ; \mathrm{D}=4 ; \mathrm{E}=5)$ and bra chest circumference $(70,75,80,85,90,95$ or $100 \mathrm{~cm})$ before and at the end of pregnancy. An increase in one bra chest circumference size results automatically in a bra cup increase of one. If a woman had 80B in early pregnancy and $85 \mathrm{C}$ at delivery, this implies an increase of two bra cup sizes (from B to $\mathrm{C}=1$ and from 80 to $85=1$ ) (13). Breast increase was dichotomized according to if bra size increased or not during pregnancy. 


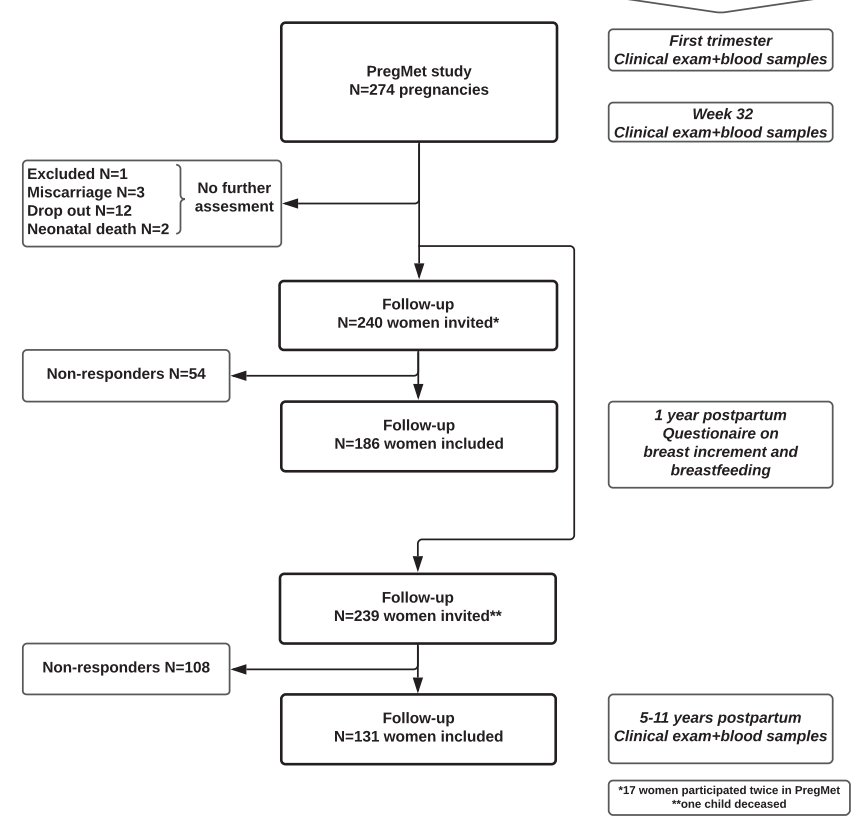

Figure 1

Flowchart with points of investigation.

Metabolic health of the participants was reassessed from April 2014 to July 2016, 5-11 years after inclusion in the PregMet study. In all, 131 (55\%) women agreed to participate in the follow-up. One hundred seventeen women met for physical examination and interview, while 14 were interviewed by phone and gave self-reported data. Metabolic characteristics which are part of the metabolic syndrome and measures of glucose homeostasis were examined. Metabolic characteristics included therefore blood pressure, anthropometric measurements, body composition, serum lipids, fasting glucose and fasting insulin. Blood pressure was measured three times, 2 min apart, with digital devices, with participant in sitting position after at least $15 \mathrm{~min}$ of chair rest. The mean of the second and third measurements was calculated. Height, waist and hip circumference were measured manually and rounded off to closest $0.5 \mathrm{~cm}$. Body composition and weight were measured using bioelectrical impedance (Inbody 720, BIOSPACE, Seoul, Korea). The examination was performed with light clothes and no shoes. InBody gives an estimate of total body fluids, proteins, minerals and fat and is validated against DEXA scan. Further details on recruitment, inclusion and procedures are described elsewhere (23). None of the women were postmenopausal when included in the follow-up. Contraceptives were not discontinued before the follow-up examination. Two were pregnant at follow-up and excluded from the analyses.

\section{Clinical trial registration}

The Clinical trial has been registered at clinicaltrials.gov: The PregMet study: NCT00159536.

\section{Laboratory analyses}

Venous blood samples were collected and processed after an overnight fast at each study site. At gestational weeks 12 and 32, a $75 \mathrm{~g}$ oral glucose tolerance test was performed. Hormonal analyses on prolactin, testosterone and androstenedione were performed at Department of Clinical Chemistry, Vejle County Hospital, Denmark. Prolactin concentrations were measured using a chemiluminescence immunoassay system (ADVIA Centaur XP; Siemens Healthineers, Siemens A/S). The method has a low cross-reaction with macroprolactin and has been standardized against the 3rd IRP WHO Reference Standard 84/500 (25). Testosterone and androstenedione were analyzed by liquid chromatography-tandem mass spectrometry (LC-MS/MS). In the analysis, plasma samples are extracted by supported liquid extraction and the eluate evaporated and reconstituted before analysis on LC-MS/MS. The analysis is calibrated by in-house prepared calibrators and the relative standard deviation is below $10 \%$. Quality is assured by monthly participation with satisfactory results in the external quality control program for steroid hormones from NEQAS, UK. Homeostatic model assessment (HOMA) IR was computed as (fasting glucose $\mathrm{mmol} / \mathrm{L} \times$ fasting insulin $\mathrm{mU} / \mathrm{L}) / 22.5$. Free testosterone index was calculated as (total testosterone/ SHBG) $\times 100$.

\section{Statistical analyses}

Baseline data were analyzed by chi-squared tests for categorical variables and two-tailed independent samples t-tests for continuous variables according to initial randomization. General linear model was used to examine the correlation of prolactin increase from first trimester to gestational week 32 and parameters of metabolic health and glucose homeostasis at week 32 of pregnancy. Additionally, median change in prolactin levels from first trimester to gestational week 32 was calculated and participants dichotomized into two groups according to prolactin change under or above the median value. Then, measures of glucose homeostasis at week 32 were analyzed with two-tailed independent samples $t$-tests according to dichotomization. General linear model was used to examine the correlation of prolactin in gestational 
week 32 and metabolic health and glucose homeostasis at follow-up. We present associations at follow-up both unadjusted and adjusted for maternal baseline BMI. Comparisons of women with or without breast increase and of prolactin levels according to original study randomization were done by two-tailed independent samples $t$-test or chi-square test as appropriate.

$P$ values $<0.05$ were considered significant. All available data were included in the analyses. Analyses were performed using Statistical Package for the Social Sciences (SPSS, version 25).

\section{Ethical approval}

Written informed consent was obtained from each participant before inclusion to the present follow-up and the declaration of Helsinki was followed throughout the study. 'The Regional Committee for Health Research Ethics of Central Norway' approved the present study 04.04.2014, reference number: 2014/96.

\section{Results}

Baseline measurements of follow-up participants at first trimester of pregnancy are presented in Table 1 . There was no difference between the groups according to original

Table 1 Baseline data from first trimester of pregnancy $(n=194)$. Data presented as mean \pm S.D. or $n(\%)$ as appropriate.

\begin{tabular}{lcc}
\hline Characteristics & Values \\
\cline { 1 - 2 } Age at first trimester (years) & $29.6 \pm 4.4$ \\
BMI (kg/m²) & $28.7 \pm 6.7$ \\
OGTT (75 g; mmol/L) & \\
$\quad$ F-glucose & & \\
2-h glucose & $5.5 \pm 0.5$ \\
F-insulin (pmol/L) & $108 \pm 78$ \\
Triglycerides (mmol/L) & $1.1 \pm 0.6$ \\
HDL cholesterol (mmol/L) & $1.6 \pm 0.4$ \\
Systolic blood pressure (mmHg) & $118 \pm 12$ \\
Diastolic blood pressure (mmHg) & $73 \pm 9.6$ \\
Total testosterone (nmol/L) & $3.1 \pm 1.7$ \\
SHBG (nmol/L) & $211 \pm 94$ \\
Androstenedione (nmol/L) & $9.0 \pm 6.0$ \\
PCOS phenotype $n(\%)$ & \\
$\quad$ Normoandrogenic & $50(26)$ \\
Hyperandrogenic & $144(74)$ \\
Smoking $n$ (\%) & $16(8)$ \\
Caucasian descent $n(\%)$ & $192(99)$ \\
\hline
\end{tabular}

BMI, body mass index; HDL, high-density lipoprotein; OGTT, oral glucose tolerance test; SHBG, sex hormone-binding globulin. study randomization (metformin vs placebo) at first trimester of pregnancy (data not shown).

Increase of prolactin from first to third trimester of pregnancy was negatively correlated to BMI $(P=0.007)$ and systolic blood pressure $(P \leq 0.001)$ at week 32 of pregnancy (Table 2). Gestational increase of prolactin was positively correlated to breast increase in pregnancy $(P=0.013)$. Women with prolactin increase above median had lower f-glucose $(P=0.041)$, f-insulin $(P=0.048)$ and HOMA-IR $(P=0.030)$ in gestational week 32 when examined according to prolactin increase above or below median (median $=125 \mu \mathrm{g} / \mathrm{L}$ ) gestational prolactin increase (Table 3).

Prolactin at gestational week 32 was negatively correlated to BMI $(P=0.044)$ and visceral fat area $(P=0.028)$ at mean 8-year follow-up in an unadjusted model (Table 4). The lower the prolactin level in third trimester, the higher were BMI and VFA at follow-up. Gestational prolactin showed no associations to metabolic health at follow-up when baseline BMI was adjusted for.

Women who reported lack of breast increase during pregnancy, had higher BMI (31.4 vs 28.4, $P=0.034)$, WHR (0.94 vs $0.89, P=0.004)$, visceral fat area ( 151.6 vs 118.9 , $P=0.050)$, total cholesterol (5.0 vs $4.6, P=0.022$ ), systolic (123 vs $117, P=0.027$ ) and diastolic blood pressure ( $81 \mathrm{vs}$ $76, P=0.011$ ) at follow-up (Table 5). Levels of testosterone,

Table 2 Correlation of prolactin increase from first trimester to week 32 in pregnancy and clinical and biochemical data at week 32 in pregnancy $(n=194)$.

\begin{tabular}{|c|c|c|c|}
\hline & \multicolumn{3}{|c|}{$\Delta$ Prolactin first trimester - week 32} \\
\hline & $\mathrm{B}$ & $\mathrm{Cl}$ & $P$ value \\
\hline Prolactin w 32 & 0.860 & 0.780 to 0.941 & $<0.001$ \\
\hline $\begin{array}{l}\text { Age at first trimester } \\
\text { (years) }\end{array}$ & -0.009 & -0.020 to 0.003 & 0.131 \\
\hline $\mathrm{BMI}\left(\mathrm{kg} / \mathrm{m}^{2}\right)$ & -0.022 & -0.038 to -0.006 & 0.007 \\
\hline Triglycerides (mmol/L) & -0.002 & -0.005 to 0.002 & 0.323 \\
\hline $\begin{array}{l}\text { HDL cholesterol } \\
\text { (mmol/L) }\end{array}$ & 0.001 & -0.001 to 0.002 & 0.335 \\
\hline $\begin{array}{l}\text { Systolic blood } \\
\text { pressure }(\mathrm{mmHg})\end{array}$ & -0.068 & -0.098 to -0.038 & $<0.001$ \\
\hline $\begin{array}{l}\text { Diastolic blood } \\
\text { pressure }(\mathrm{mmHg})\end{array}$ & -0.023 & -0.051 to 0.004 & 0.098 \\
\hline $\begin{array}{l}\text { Breast increase in } \\
\text { pregnancy* }\end{array}$ & 0.003 & 0.001 to 0.005 & 0.013 \\
\hline $\begin{array}{l}\text { Total testosterone } \\
(\mathrm{nmol} / \mathrm{L})\end{array}$ & 0.004 & -0.002 to 0.010 & 0.196 \\
\hline SHBG (nmol/L) & 0.257 & -0.019 to 0.532 & 0.068 \\
\hline $\begin{array}{l}\text { Androstenedione } \\
(\mathrm{nmol} / \mathrm{L})\end{array}$ & 0.013 & -0.002 to 0.028 & 0.101 \\
\hline
\end{tabular}


Table 3 Glucose homeostasis at week 32 of pregnancy according to median change of prolactin from first trimester to week 32 of pregnancy $(n=194)$. Data presented as mean $(\mathrm{Cl})$.

\begin{tabular}{|c|c|c|c|}
\hline & \multicolumn{2}{|c|}{ Median $\Delta$ prolactin $=125 \mu \mathrm{g} / \mathrm{I}(94-149)$} & \multirow[b]{2}{*}{$P$ value } \\
\hline & $\begin{array}{c}<\text { Median change } \\
\quad(n=99)\end{array}$ & $\begin{array}{c}>\text { Median change } \\
\quad(n=95)\end{array}$ & \\
\hline $\begin{array}{l}\text { F-glucose } \\
\text { (mmol/L) }\end{array}$ & $4.5(4.3-4.6)$ & $4.3(4.2-4.5)$ & 0.041 \\
\hline $\begin{array}{r}\text { 2-h glucose } \\
(\mathrm{mmol} / \mathrm{L})\end{array}$ & $6.3(6.0-6.5)$ & $6.1(5.8-6.4)$ & 0.300 \\
\hline $\begin{array}{l}\text { F-insulin } \\
\quad(\mathrm{pmol} / \mathrm{L})\end{array}$ & $152(139-165)$ & $132(145-150)$ & 0.048 \\
\hline HOMA-IR & $30.8(27.8-33.7)$ & $25.6(22.3-28.8)$ & 0.030 \\
\hline
\end{tabular}

Independent samples $t$-test were used to compare groups. HOMA-IR, homeostasis model assessment-insulin resistance.

SHBG and androstenedione in pregnancy and at follow-up were not associated to either prolactin or breast increase in pregnancy. Prolactin at follow-up tended to be higher in women with breast increase during pregnancy, but the difference did not reach level of significance. Metformin use from first trimester and onwards during pregnancy, had no effect on serum prolactin level at gestational week 32 (162 vs 163) or prolactin increase from first trimester to gestational week 32 (120 vs 125) compared to placebo (Table 6).

\section{Discussion}

In pregnant women with PCOS, increase of prolactin was negatively correlated to BMI and systolic blood pressure in third trimester of pregnancy. Women with prolactin increase above median had better glucose regulation in third trimester of pregnancy. Prolactin was negatively correlated to BMI and VFA at follow-up, but after adjustment for baseline BMI, none of these associations remained significant. Breast increase during pregnancy was associated with better long-term metabolic health expressed by more favorable anthropometric measures, lower blood pressure and total cholesterol at follow-up.

Measures of glucose homeostasis in third trimester of pregnancy were analyzed according to prolactin increase above or below median prolactin increase. Participants were under strict surveillance for development of gestational diabetes mellitus (GDM) throughout pregnancy in the original RCT. If GDM was detected, additional treatment was initiated according to contemporary national guidelines. Theoretically, this could result in a plateau of f-glucose and we could therefore not assume linearity in our handling of variables of glucose homeostasis during pregnancy.

Prolactin may be a primary effector or a marker of metabolic health in pregnancy. Dopamine inhibits the active spontaneous secretion of pituitary prolactin. Circulating prolactin mainly affects peripheral tissue, but prolactin also activates prolactin receptors (PRL-R) in dopaminergic neurons and thereby regulates its own release by a short-loop negative feedback mechanism. Less dopamine is secreted during pregnancy. The reduced dopamine results in hyperprolactinemia, probably via alterations in signaling pathways downstream of the PRL-R in neuroendocrine dopaminergic neurons (26). Insulin seems to be involved, directly or indirectly, in the regulation of prolactin secretion. Our findings of

Table 4 Association of prolactin at week 32 of pregnancy and clinical and biochemical data at 8-year follow-up ( $n=105)$.

\begin{tabular}{|c|c|c|c|c|c|c|}
\hline & \multicolumn{3}{|c|}{ Prolactin week 32} & \multicolumn{3}{|c|}{$\begin{array}{c}\text { Prolactin week 32, adjusted for first } \\
\text { trimester BMI }\end{array}$} \\
\hline & $\mathrm{B}$ & $\mathrm{Cl}$ & $P$ value & $\mathrm{B}$ & $\mathrm{Cl}$ & $P$ value \\
\hline $\mathrm{BMI}\left(\mathrm{kg} / \mathrm{m}^{2}\right)$ & -0.023 & -0.046 to -0.001 & 0.044 & -0.001 & -0.014 to 0.013 & 0.935 \\
\hline Waist circumference (cm) & -0.039 & -0.088 to 0.010 & 0.119 & 0.001 & -0.038 to 0.039 & 0.975 \\
\hline Visceral fat area $\left(\mathrm{cm}^{2}\right)$ & -0.266 & -0.502 to -0.030 & 0.028 & -0.065 & -0.247 to 0.116 & 0.474 \\
\hline F-glucose (mmol/L) & $<0.001$ & -0.002 to 0.001 & 0.654 & $<0.001$ & -0.002 to 0.002 & 0.956 \\
\hline F-insulin (pmol/L) & -0.009 & -0.033 to 0.016 & 0.482 & 0.001 & -0.023 to 0.025 & 0.925 \\
\hline HOMA-IR & -0.002 & -0.007 to 0.004 & 0.595 & 0.001 & -0.005 to 0.006 & 0.805 \\
\hline Triglycerides (mmol/L) & -0.001 & -0.002 to 0.001 & 0.401 & $<0.001$ & -0.002 to 0.001 & 0.640 \\
\hline HDL cholesterol (mmol/L) & 0.001 & -0.001 to 0.002 & 0.368 & $<0.001$ & -0.001 to 0.002 & 0.715 \\
\hline Systolic blood pressure (mmHg) & -0.020 & -0.070 to 0.031 & 0.439 & -0.004 & -0.055 to 0.046 & 0.866 \\
\hline Diastolic blood pressure (mmHg) & -0.014 & -0.051 to 0.024 & 0.417 & -0.003 & -0.040 to 0.035 & 0.888 \\
\hline Total testosterone (nmol/L) & 0.001 & -0.001 to 0.003 & 0.214 & 0.001 & -0.001 to 0.004 & 0.238 \\
\hline SHBG (nmol/L) & -0.011 & -0.118 to 0.095 & 0.832 & -0.012 & -0.123 to 0.099 & 0.827 \\
\hline Androstenedione (nmol/L) & 0.007 & 0.000 to 0.015 & 0.057 & -0.006 & -0.001 to 0.014 & 0.108 \\
\hline
\end{tabular}

Linear regression analyses, prolactin week 32 as independent variable.

BMI, body mass index; HDL, high-density lipoprotein; HOMA-IR, homeostasis model assessment-insulin resistance; SHBG, sex hormone-binding globulin. 
Table 5 Metabolic health at 5-11 years follow-up according to breast increase (yes/no) during pregnancy $(n=103)$. Data are presented as mean \pm S.D. or $n(\%)$ as appropriate.

\begin{tabular}{|c|c|c|c|}
\hline & $\begin{array}{c}\text { Lack of breast } \\
\text { increase } \\
(n=33)\end{array}$ & $\begin{array}{c}\text { Breast } \\
\text { increase } \\
(n=70)\end{array}$ & $P$ value \\
\hline Age at follow-up & $38.8(3.9)$ & $37.5(4.4)$ & 0.157 \\
\hline BMI $\left(k g / m^{2}\right)$ & $31.4(6.9)$ & $28.4(6.7)$ & 0.034 \\
\hline Waist/hip ratio & $0.94(0.07)$ & $0.89(0.07)$ & 0.004 \\
\hline $\begin{array}{l}\text { Visceral fat area } \\
\left(\mathrm{cm}^{2}\right)\end{array}$ & $151.6(73.5)$ & 118.9 (59.3) & 0.050 \\
\hline F-glucose (mmol/L) & $5.3(0.8)$ & $5.1(0.5)$ & 0.196 \\
\hline F-insulin (pmol/L) & $91(60)$ & $78(53)$ & 0.306 \\
\hline HOMA-IR & $2.8(1.7)$ & $2.7(1.8)$ & 0.734 \\
\hline $\begin{array}{l}\text { Total cholesterol } \\
\text { (mmol/L) }\end{array}$ & $5.0(0.9)$ & $4.6(0.7)$ & 0.022 \\
\hline $\begin{array}{l}\text { Triglycerides } \\
\text { (mmol/L) }\end{array}$ & $1.2(0.7)$ & $1.0(0.5)$ & 0.105 \\
\hline $\begin{array}{l}\text { HDL cholesterol } \\
\text { (mmol/L) }\end{array}$ & $1.5(0.4)$ & $1.5(0.4)$ & 0.612 \\
\hline $\begin{array}{l}\text { Systolic blood } \\
\text { pressure }(\mathrm{mmHg})\end{array}$ & $123(16)$ & $117(11)$ & 0.027 \\
\hline $\begin{array}{l}\text { Diastolic blood } \\
\text { pressure }(\mathrm{mmHg})\end{array}$ & $81(11)$ & $76(8)$ & 0.011 \\
\hline $\begin{array}{l}\text { Total testosterone } \\
(\mathrm{nmol} / \mathrm{L})\end{array}$ & $1.2(0.8)$ & $1.1(0.6)$ & 0.730 \\
\hline SHBG (nmol/L) & $58(38)$ & $50(24)$ & 0.252 \\
\hline $\begin{array}{l}\text { Androstendione } \\
(\mathrm{nmol} / \mathrm{L})\end{array}$ & $4.9(2.7)$ & $4.6(2.2)$ & 0.591 \\
\hline Prolactin $(\mu \mathrm{g} / \mathrm{l})$ & $8.3(3.8)$ & $12.4(20.8)$ & 0.289 \\
\hline Smoking, $n(\%)$ & $4(12)$ & $6(9)$ & 0.724 \\
\hline $\begin{array}{l}\text { Current use of } \\
\quad \text { metformin, } n(\%)\end{array}$ & $4(12)$ & $5(7)$ & 0.463 \\
\hline
\end{tabular}

Independent samples $t$-test and chi-square test were used to compare study groups.

BMI, body mass index; HDL, high-density lipoprotein; HOMA-IR, homeostasis model assessment-insulin resistance; SHBG, sex hormonebinding globulin; TG, triglyceride.

better glucose regulation and less insulin resistance in women with high increase of circulating prolactin during pregnancy might imply that the neuroendocrine adaptation allowing physiological increase of prolactin during pregnancy is influenced by glucose metabolism. Our findings that prolactin level in gestational week 32 was inversely correlated with BMI and visceral adiposity at follow-up further strengthen the suggestion that low prolactin in late pregnancy may act as a adiposity mediated marker of future impaired metabolic health. We are not aware of previous studies, which can explain our findings. Prolactin does stimulate $\beta$-cell proliferation in pancreatic islets as a physiological adaptation to the increasing insulin resistance that emerges during pregnancy and prolactin also reduces B-cell apoptosis when studied in vitro $(9,27)$. There is thus a theoretical basis for considering prolactin as a protective factor against later diabetes.

It is intriguing that a crude measurement of breast increase in pregnancy can identify difference in metabolic profile also later in life. We have previously reported inferior metabolic health in both first and third trimester of pregnancy and less breastfeeding in women with PCOS, who did not experience breast increase while pregnant (13).

These results point to a link between metabolic health and both prolactin levels and breast increase, and contradict the understanding that breastfeeding per se improves future metabolic health by reducing maternal postpartum weight retention and lowering the risk of obesity, type 2 diabetes and metabolic syndrome later in life $(28,29)$. We suggest that these observations are explained by 'reverse causality'. Poor metabolic health prior to, and during, pregnancy had a negative effect on breastfeeding ability, demonstrated by lower gestational prolactin levels and no breast increase. These women also demonstrate poor long-term metabolic health measured as BMI, central obesity and higher blood pressure. These findings are in line with the results from a recently published large longitudinal cohort study, indicating pre-pregnancy metabolic health as main determinant of both breastfeeding and long-term maternal metabolic health (30).

Metformin had no impact on either increase of prolactin in pregnancy or prolactin levels in week 32 of pregnancy. Long-term administration of metformin in insulin-resistant non-pregnant women with PCOS, resulted in decrease of insulin and increase in prolactin (31). Prolactin secretion in the non-pregnant state is regulated by inhibition, predominantly by dopamine.

Table 6 Prolactin levels in women with PCOS according to original study group (metformin and placebo). Data are presented as mean (Cl) for groups and mean (min-max) for all.

\begin{tabular}{|c|c|c|c|}
\hline & Metformin $(n=97)$ & Placebo $(n=97)$ & All \\
\hline First trimester prolactin ( $\mu \mathrm{g} / \mathrm{L})$ & $43(36-49)$ & $38(32-44)$ & $40(7-234)$ \\
\hline Third trimester prolactin $(\mu \mathrm{g} / \mathrm{L})$ & $162(150-174)$ & $163(152-174)$ & $162(10-438)$ \\
\hline Prolactin increase from first to third trimester $(\mu \mathrm{g} / \mathrm{L})$ & $120(109-130)$ & $125(113-136)$ & $122(-129$ to 339$)$ \\
\hline
\end{tabular}


The authors linked this observation to normalization of hypothalamic dopaminergic tone (31). In pregnancy however, randomized, placebo controlled studies reported no effect of metformin on glucose metabolism, that is prevention of GDM or need of additional insulin treatment $(19,22,32,33,34)$. These observations are in line with the finding of no effect of metformin on prolactin in pregnancy.

\section{Strengths and limitations}

The strengths of the study were the well-characterized cohort of women with PCOS diagnosed in accordance with the Rotterdam criteria. The cohort studied represents women with all four PCOS phenotypes and not only a selected group of PCOS women needing ART. Participants in the follow-up were representative of the original study population. To our knowledge, this is the first study with a prospective design investigating the association between prolactin and breast increase in pregnancy and later metabolic health.

The main limitation of the study was the sample size. A higher participation rate at follow-up would have been desired. Breast increase was self-reported and a rather rough estimate, possibly also prone to bias.

In conclusion, high prolactin levels and breast increase in pregnancy were associated with a more favorable long-term metabolic health in women with PCOS. Low prolactin and no breast increase may serve as a marker of inferior metabolic health. Both prolactin and breast increase seem to be BMImediated markers.

\section{Declaration of interest}

Marianne Skovsager Andersen is on the editorial board of EJE. Marianne Skovsager Andersen was not involved in the review or editorial process for this paper, on which she is listed as an author. The other authors have nothing to disclose.

\section{Funding}

This work was supported by The Research Council of Norway (registration number: 239987), Novo Nordisk Foundation Norway and the Norwegian University of Science and Technology/St. Olavs University Hospital-trust. Weifa AS, who supplied the drug free of charge for use in the PregMet study, and Novo Nordisk Foundation had no role in collection, analysis and interpretation of data or writing the primary reports from these studies and was in no way involved in this follow-up study.

Author contribution statement

M S Andersen and E Vanky: Shared last authorship.

\section{References}

1 March WA, Moore VM, Willson KJ, Phillips DIW, Norman RJ \& Davies MJ. The prevalence of polycystic ovary syndrome in a community sample assessed under contrasting diagnostic criteria. Human Reproduction 201025 544-551. (https://doi.org/10.1093/ humrep/dep399)

2 Diamanti-Kandarakis E \& Dunaif A. Insulin resistance and the polycystic ovary syndrome revisited: an update on mechanisms and implications. Endocrine Reviews 201233 981-1030. (https://doi. org/10.1210/er.2011-1034)

3 Glintborg D, Henriksen JE, Andersen M, Hagen C, Hangaard J, Rasmussen PE, Schousboe K \& Hermann AP. Prevalence of endocrine diseases and abnormal glucose tolerance tests in 340 Caucasian premenopausal women with hirsutism as the referral diagnosis. Fertility and Sterility 200482 1570-1579. (https://doi.org/10.1016/j. fertnstert.2004.06.040)

4 Glintborg D, Rubin KH, Nybo M, Abrahamsen B \& Andersen M. Cardiovascular disease in a nationwide population of Danish women with polycystic ovary syndrome. Cardiovascular Diabetology 201817 37. (https://doi.org/10.1186/s12933-018-0680-5)

5 Roos N, Kieler H, Sahlin L, Ekman-Ordeberg G, Falconer H \& Stephansson O. Risk of adverse pregnancy outcomes in women with polycystic ovary syndrome: population based cohort study. BMJ 2011 343 d6309. (https://doi.org/10.1136/bmj.d6309)

6 Kjerulff LE, Sanchez-Ramos L \& Duffy D. Pregnancy outcomes in women with polycystic ovary syndrome: a metaanalysis. American Journal of Obstetrics and Gynecology 2011204 558.e1-558.e6. (https:// doi.org/10.1016/j.ajog.2011.03.021)

7 Boomsma CM, Eijkemans MJC, Hughes EG, Visser GHA, Fauser BCJM \& Macklon NS. A meta-analysis of pregnancy outcomes in women with polycystic ovary syndrome. Human Reproduction Update 200612 673-683. (https://doi.org/10.1093/humupd/dml036)

8 Palm CVB, Glintborg D, Kyhl HB, McIntyre HD, Jensen RC, Jensen TK, Jensen DM \& Andersen M. Polycystic ovary syndrome and hyperglycaemia in pregnancy. A narrative review and results from a prospective Danish cohort study. Diabetes Research and Clinical Practice 2018145 167-177. (https://doi.org/10.1016/j. diabres.2018.04.030)

9 Baeyens L, Hindi S, Sorenson RL \& German MS. Beta-Cell adaptation in pregnancy. Diabetes, Obesity and Metabolism 201618 (Supplement 1) 63-70. (https://doi.org/10.1111/dom.12716)

10 Glintborg D, Altinok M, Mumm H, Buch K, Ravn P \& Andersen M. Prolactin is associated with metabolic risk and cortisol in 1007 women with polycystic ovary syndrome. Human Reproduction 2014 29 1773-1779. (https://doi.org/10.1093/humrep/deu133)

11 Wang T, Lu J, Xu Y, Li M, Sun J, Zhang J, Xu B, Xu M, Chen Y, Bi Y et al. Circulating prolactin associates with diabetes and impaired glucose regulation: a population-based study. Diabetes Care 201336 1974-1980. (https://doi.org/10.2337/dc12-1893)

12 Therkelsen KE, Abraham TM, Pedley A, Massaro JM, Sutherland P, Hoffmann U \& Fox CS. Association between prolactin and incidence of cardiovascular risk factors in the Framingham heart study. Journal of the American Heart Association 20165 e002640. (https://doi. org/10.1161/JAHA.115.002640)

13 Vanky E, Nordskar JJ, Leithe H, Hjorth-Hansen AK, Martinussen M \& Carlsen SM. Breast size increment during pregnancy and breastfeeding in mothers with polycystic ovary syndrome: a follow-up study of a randomised controlled trial on metformin versus placebo. BJOG 2012119 1403-1409. (https://doi.org/10.1111/ j.1471-0528.2012.03449.x)

14 Turcksin R, Bel S, Galjaard S \& Devlieger R. Maternal obesity and breastfeeding intention, initiation, intensity and duration: a systematic review. Maternal and Child Nutrition $201410166-183$. (https://doi.org/10.1111/j.1740-8709.2012.00439.x) 
15 Winkvist A, Brantsaeter AL, Brandhagen M, Haugen M, Meltzer HM \& Lissner L. Maternal prepregnant body mass index and gestational weight gain are associated with initiation and duration of breastfeeding among Norwegian mothers. Journal of Nutrition 2015 145 1263-1270. (https://doi.org/10.3945/jn.114.202507)

16 Vanky E, Isaksen H, Moen MH \& Carlsen SM. Breastfeeding in polycystic ovary syndrome. Acta Obstetricia et Gynecologica Scandinavica 200887 531-535. (https://doi. org/10.1080/00016340802007676)

17 Joham AE, Nanayakkara N, Ranasinha S, Zoungas S, Boyle J, Harrison CL, Forder P, Loxton D, Vanky E \& Teede HJ. Obesity, polycystic ovary syndrome and breastfeeding: an observational study. Acta Obstetricia et Gynecologica Scandinavica 201695 458-466. (https://doi.org/10.1111/aogs.12850)

18 Teede HJ, Misso ML, Costello MF, Dokras A, Laven J, Moran L, Piltonen T, Norman RJ \& International PCOS Network. Recommendations from the international evidence-based guideline for the assessment and management of polycystic ovary syndrome. Clinical Endocrinology 201889 251-268. (https://doi.org/10.1111/cen.13795)

19 Lovvik TS, Carlsen SM, Salvesen Ø, Steffensen B, Bixo M, GomezReal F, Lonnebotn M, Hestvold KV, Zabielska R, Hirschberg AL et al. Use of metformin to treat pregnant women with polycystic ovary syndrome (PregMet2): a randomised, double-blind, placebocontrolled trial. Lancet: Diabetes and Endocrinology 20197 256-266. (https://doi.org/10.1016/S2213-8587(19)30002-6)

20 Pinola P, Puukka K, Piltonen TT, Puurunen J, Vanky E, SundstromPoromaa I, Stener-Victorin E, Linden Hirschberg A, Ravn P, Skovsager Andersen $\mathrm{M}$ et al. Normo- and hyperandrogenic women with polycystic ovary syndrome exhibit an adverse metabolic profile through life. Fertility and Sterility 2017 107 788-795.e2. (https://doi. org/10.1016/j.fertnstert.2016.12.017)

21 Daan NMP, Louwers YV, Koster MPH, Eijkemans MJC, de Rijke YB, Lentjes EWG, Fauser BCJM \& Laven JSE. Cardiovascular and metabolic profiles amongst different polycystic ovary syndrome phenotypes: who is really at risk? Fertility and Sterility 20141021444. e3-1451.e3. (https://doi.org/10.1016/j.fertnstert.2014.08.001)

22 Vanky E, Stridsklev S, Heimstad R, Romundstad P, Skogoy K, Kleggetveit O, Hjelle S, von Brandis P, Eikeland T, Flo K et al. Metformin versus placebo from first trimester to delivery in polycystic ovary syndrome: a randomized, controlled multicenter study. Journal of Clinical Endocrinology and Metabolism 201095 E448-E455. (https://doi.org/10.1210/jc.2010-0853)

23 Underdal MO, Stridsklev S, Oppen IH, Hogetveit K, Andersen MS \& Vanky E. Does metformin treatment during pregnancy modify the future metabolic profile in women With PCOS? Journal of Clinical Endocrinology and Metabolism 2018103 2408-2413. (https://doi. org/10.1210/jc.2018-00485)

24 Rotterdam ESHRE/ASRM-Sponsored PCOS Consensus Workshop Group. Revised 2003 consensus on diagnostic criteria and long-term health risks related to polycystic ovary syndrome. Fertility and Sterility 200481 19-25. (https://doi.org/10.1016/j.fertnstert.2003.10.004)

25 Hattori N, Aisaka K \& Shimatsu A. A possible cause of the variable detectability of macroprolactin by different immunoassay systems. Clinical Chemistry and Laboratory Medicine 201654 603-608. (https:// doi.org/10.1515/cclm-2015-0484)

26 Grattan DR, Steyn FJ, Kokay IC, Anderson GM \& Bunn SJ. Pregnancyinduced adaptation in the neuroendocrine control of prolactin secretion. Journal of Neuroendocrinology 200820 497-507. (https:// doi.org/10.1111/j.1365-2826.2008.01661.x)

27 Terra LF, Garay-Malpartida MH, Wailemann RAM, Sogayar MC \& Labriola L. Recombinant human prolactin promotes human beta cell survival via inhibition of extrinsic and intrinsic apoptosis pathways. Diabetologia 201154 1388-1397. (https://doi.org/10.1007/s00125011-2102-z)

28 Baker JL, Gamborg M, Heitmann BL, Lissner L, Sorensen TI \& Rasmussen KM. Breastfeeding reduces postpartum weight retention. American Journal of Clinical Nutrition 200888 1543-1551. (https:// doi.org/10.3945/ajcn.2008.26379)

29 Ram KT, Bobby P, Hailpern SM, Lo JC, Schocken M, Skurnick J \& Santoro N. Duration of lactation is associated with lower prevalence of the metabolic syndrome in midlife - SWAN, the study of women's health across the nation. American Journal of Obstetrics and Gynecology 2008198 268.e1-268.e6. (https://doi.org/10.1016/j. ajog.2007.11.044)

30 Velle-Forbord V, Skrastad RB, Salvesen Ø, Kramer MS, Morken NH \& Vanky E. Breastfeeding and long-term maternal metabolic health in the HUNT study: a longitudinal population-based cohort study. BJOG 2019126 526-534. (https://doi.org/10.1111/1471-0528.15538)

31 Ortega-Gonzalez C, Cardoza L, Coutino B, Hidalgo R, ArteagaTroncoso G \& Parra A. Insulin sensitizing drugs increase the endogenous dopaminergic tone in obese insulin-resistant women with polycystic ovary syndrome. Journal of Endocrinology 2005184 233-239. (https://doi.org/10.1677/joe.1.05844)

32 Syngelaki A, Nicolaides KH, Balani J, Hyer S, Akolekar R, Kotecha R, Pastides A \& Shehata H. Metformin versus placebo in obese pregnant women without diabetes mellitus. New England Journal of Medicine 2016374 434-443. (https://doi.org/10.1056/NEJMoa1509819)

33 Chiswick C, Reynolds RM, Denison F, Drake AJ, Forbes S, Newby DE, Walker BR, Quenby S, Wray S, Weeks A et al. Effect of metformin on maternal and fetal outcomes in obese pregnant women (EMPOWaR): a randomised, double-blind, placebo-controlled trial. Lancet: Diabetes and Endocrinology 20153 778-786. (https://doi.org/10.1016/S22138587(15)00219-3)

34 Valdes E, Sepulveda-Martinez A, Candia P, Abusada N, Orellana R, Manukian B \& Cuellar E. Metformin as a prophylactic treatment of gestational diabetes in pregnant patients with pregestational insulin resistance: a randomized study. Journal of Obstetrics and Gynaecology Research 201844 81-86. (https://doi.org/10.1111/jog.13477)

Received 2 January 2019

Revised version received 25 March 2019

Accepted 16 April 2019 